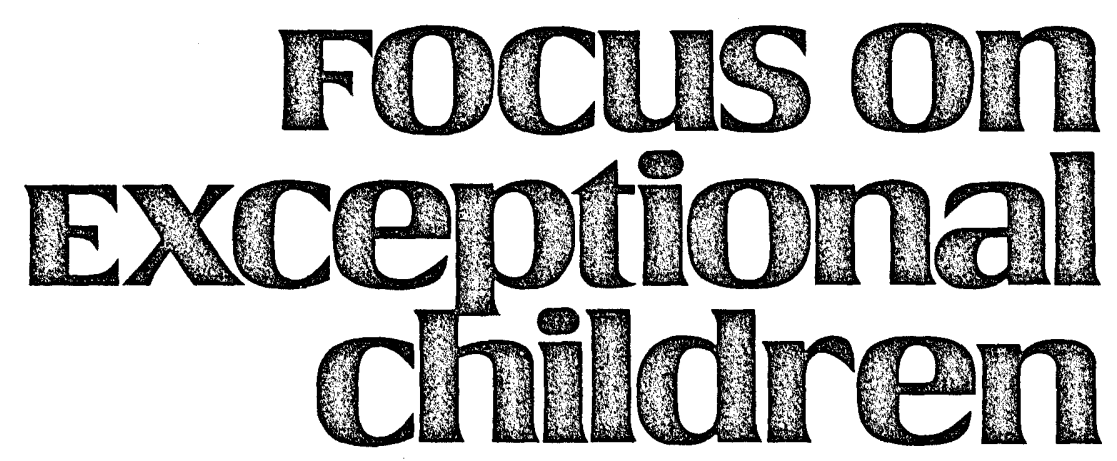

\title{
Guidelines for Assessment in Special Education
}

\author{
George B. Helton
}

Assessment in special education is useful when it helps us make decisions that promote appropriate and effective services to students. In particular, assessment should assist us in making two general types of decisions: (1) who should be served? (classification decisions); and (2) how should eligible students be served? (programming decisions).

Although all of us involved in special education recognize that assessment is crucially involved in our efforts to make appropriate classification and programming decisions, we are often much less sure about how to provide helpful assessment services. We ask questions such as: How should we organize our assessment program? How can we assess all the students who need it and still ensure quality assessment work? What assessment techniques should be used with different types of students?

The specific suggestions in this article may be more easily applied in some school systems than in others. This caution reflects several important points. One is that assessment requires integration of a number of factors including goals of assessment, legal requirements, ethical responsibilities, and available assessment techniques (Helton, Workman, \& Matúszek, 1982, pp. 1-2). Partly because of the need to integrate so many factors, assessment is a complex activity, subject to varied emphases and interpretations. It is also an activity that generates much controversy about specific theoretical and applied issues. Hence, each professional involved in assessment and each school system must ultimately make judgments about the varied emphases, interpretations, and viewpoints, rather than depending on others for "packaged" answers. And, of course, a genuine concern for our students and honest teamwork are necessary in any assessment program.

Dr. Helton is Associate Professor of Psychology and Coordinator of the Graduate Program in School Psychology at the University of Tennessee at Chattanooga. He formerly held positions as a school psychologist and as a school administrator.

๑) Love Publishing Company, 1984. 


\section{FACTORS TO BE INTEGRATED IN ASSESSMENT}

\section{Goals of Assessment}

\section{Classification Decisions}

Classification decisions, one of the two general types, essentially involve determining whether or not each assessed student has one of the handicapping conditions listed in the regulations implementing Public Law 94142 (Education of Handicapped Children, 1977). Specific categories of students eligible for special education and related services under these regulations are:

... mentally retarded, hard of hearing, deaf, speech impaired, visually handicapped, seriously emotionally disturbed, orthopedically impaired, other health impaired, deafblind, multi-handicapped, or as having specific learning disabilities. (p. 42478)

Although the regulations implementing PL 94-142 also define each of these handicapping conditions, each state department of education may specify more exact criteria for classifying students as handicapped. These criteria

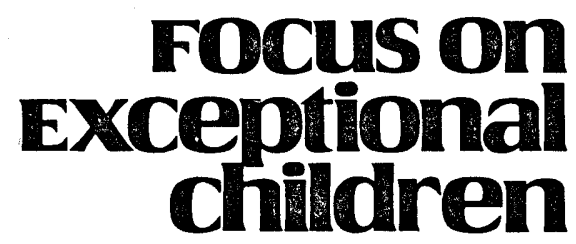

FOCUS ON EXCEPTIONAL CHILDREN (ISSN 0015-511X) (USPS 203-360) is published monthly except June, July, and August as a service to teachers, special educators, curriculum specialists, administrators, and those concerned with the special education of exceptional children. This journai is abstracted and indexed in Exceptional Child Education Resources, and is also available in microform from Xerox University Microfilms, Ann Arbor, Michigan. Subscription rates, $\$ 18.00$ per year. Copyright $\odot 1984$, Love Publishing Company. All rights reserved. Reproduction in whole or part without written permission is prohibited. Printed in the United States of America. Second class postage is paid at Denver, Colorado. POSTMASTER: Send address changes to:

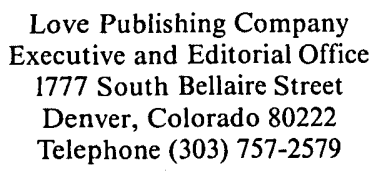

EDITORIAL BOARD
Edward L. Meyen University of Kansas
Glenn A. Vergason Georgia State University
Richard J. Whelan University of Kansas Medical Center must be compatible with the definitions of the handicapping conditions in the regulations implementing PL 94-142. In actual practice, then, classification decisions involve determining whether assessed students meet the criteria used in a particular state for particular handicapping conditions. Since the eligibility criteria for specific handicapping conditions vary from state to state, a student receiving special education services in one state may become ineligible for these services if he or she moves to another state. For instance, a student receiving special education services as a learning disabled student in Georgia might not be classifiable as learning disabled when moving to Tennessee. These situations are confusing and distressing.

Each state also has the right to recognize categories of exceptionality that are not mentioned in the regulations implementing PL 94-142. To illustrate, Tennessee state law recognizes intellectual giftedness as a category of exceptionality. Therefore, special education and support services personnel in Tennessee are required to provide classification and programming services to these students, as well as to students with the handicapping conditions recognized in the regulations implementing PL 94-142.

\section{Programming Decisions}

In contrast to classification decisions, programming decisions require us to identify areas in which students classified as exceptional require special education and related services. These areas of need and specific services to address them are incorporated into an individualized education program (IEP), which is basically a service plan, for each eligible student. According to the regulations implementing PL 94-142, an IEP is to be developed by a team including the student's regular classroom teacher, special education personnel, personnel knowledgable of assessment, and one or both of the student's parents.

Assessment as an aid to classification and programming decisions must be responsive to other legal requirements and to ethical concerns as well. In addition, literally dozens of assessment techniques are available. Some are more appropriate to classification decisions, and others are more appropriate to programming decisions (Coulter, 1980). In light of these considerations, choices about assessment programs and specific assessment practices must be made carefully.

Weatherly and Lipsky (1977) have contended-and I agree-that assessment is easily corrupted, most crucially when its focus is shifted from the needs of 
students to the needs of school systems and school personnel. Those authors cited examples of such corruption, including "scheduling of assessments in favor of children who had behavior problems, who were not likely to cost the system money, or who met the needs of school personnel seeking to practice their individual specialties" (p. 194). Assessment must serve the needs of school systems and school personnel as well as the needs of students, but it should be concerned primarily with the needs of students. Otherwise we may be abiding by the letter of PL 94-142 while neglecting its spirit.

Further, I believe that assessment should place as much emphasis on determining which students are ineligible for special education services as it does on determining which students are eligible for these services. This is a controversial stance. On the one hand, numerous court cases have focused on allegations of misclassification of ethnic minority students as handicapped (c.f., Reschly, 1983), and the regulations implementing PL 94-142 contain a number of requirements for nondiscriminatory assessment and classification of students. On the other hand, students may not receive needed services unless those services are provided by special education programs.

The dilemma involved in providing nondiscriminatory assessment and classification services and, at the same time, providing needed educational and related services to students is perhaps illustrated in a study by Algozzine and Ysseldyke (1981). They found that slightly more than one-half of school staff members in that study judged children as handicapped even though all assessment results for each case presented were within the normal range. Algozzine and Ysseldyke suggested that their findings may indicate concerns about the ability of regular education to adequately serve students referred for assessment, and a corresponding tendency to overdefine who is handicapped.

In contrast, I advocate efforts to make regular education better able to serve a wider variety of students, as well as a continuing emphasis on compensatory education services for economically disadvantaged students. I also advocate that all of us continue to work hard to make special education services more effective for eligible handicapped students. Achieving this goal might lessen the dilemmas involved in special education classification, since classification of students as handicapped can be more easily justified if it is highly likely to lead to effective services.

Finally, I believe that assessment must lead to better programming decisions than it has in the past. Historically, the emphasis in assessment has been on assessment for classification (Helton, Morrow, \& Yates, 1977). Though the classification function of assessment cannot be slighted (Helton et al., 1982, xv), the welfare of our students, as well as increasing accountability requirements, demands better assessment for programming (Kaufman, 1983). Our task, then, is to assess students more effectively for both classification and programming-a difficult but unavoidable challenge.

\section{Legal Requirements in Assessment}

The regulations implementing PL 94-142 include a number of requirements for assessment practice. These can be grouped in terms of students to receive assessment services, assessment for classification, assessment for programming, and procedural requirements.

\section{Students to Receive Assessment Services}

PL 94-142 requires that a free and appropriate education be provided to persons ages 3 through 21 who demonstrate handicapping conditions listed in the regulations implementing the law. School systems, however, are not responsible for providing services to 3 through 5 year-olds and 18 through 21 year-olds if services to persons in those age groups are contrary to state law or court order. The regulations implementing PL 94-142 also require that school systems attempt to identify persons who are or will be eligible for special education services. These "child find" efforts must include persons from birth through age 21 (Helton et al., 1982, p. 47). "Child find" activities and special education services involve assessment for persons in the specified age ranges.

\section{Assessment for Classification}

A number of provisions in the regulations implementing PL 94-142 are relevant to assessment for classification:

1. Assessment is to be conducted in all areas related to the suspected disability, including, where appropriate, health, vision, hearing, social and emotional status, general intelligence, academic performance, communicative status, and motor abilities.

2. No single evaluation procedure can be used as the sole basis for making decisions about students.

3. Tests and other methods of evaluating a student must be administered in that student's native 
language unless this procedure is clearly not feasible.

4. Tests must be administered by qualified personnel who follow the instructions provided by test producers (qualified personnel refers to persons recognized by state departments of education as competent to perform various assessment activities.

5. Test data are not to be interpreted as reflecting poor aptitude or achievement when test scores actually reflect students' sensory, manual, or speech impairments.

6. Tests and other evaluative measures must be validated for the specific purposes for which they are used.

7. Each student receiving special education services must be reassessed at least every 3 years (more frequently if needed or requested by the teacher or parent), and reassessments must conform to the requirements noted above.

Specific wording for each of these requirements may be found in the Federal Register (Education of Handicapped Children, 1977, pp. 42496-42497).

These requirements are intended to promote a goal of nondiscriminatory assessment by ensuring that asessment is comprehensive, conducted by qualified personnel, incorporates appropriate tests, and is repeated periodically. While none of us can argue with the goal of "fair" assessment (particularly with ethnic minority, linguistically different, and culturally different students), these requirements are extremely difficult to honor. For one thing, assessment of all areas related to a student's suspected disability can be quite time-consuming. Similarly, reassessing each student receiving special education services at least every 3 years is also timeconsuming. Third, some school systems (especially in rural areas) have difficulty locating and employing qualified personnel. In addition, generally qualified personnel may not be able to assess students in their native languages. Even if this is possible with a specific student, it is inappropriate if the norms of the test to be given were developed by giving the test in English (see Helton et al., 1982, pp. 68-69). Finally, there is little agreement on what is required to validate a test for a specific purpose.

Federal courts are now involved in questions of test validation and do not always come to the same conclusions. Consider the Larry P. v. Riles (1979) case and the PASE v. Hannon (1980) case. In the former the court held that standardized intelligence tests (such as the Stanford-Binet Intelligence Scale and the Wechsler
Intelligence Scale for Children-Revised) had not been sufficiently validated for use in determining whether black students could be classified as mentally retarded. In the latter case the court held that these same tests could be used in making this type of classification decisions. Ultimately, the U.S. Supreme Court will likely be forced to deal with such questions.

At this point, one may be tempted to conclude that the unanswered questions and practical problems are too numerous to allow implementation of beneficial and legally appropriate assessment programs. I do not agree. Instead, I believe that a number of steps can be taken to help us achieve this goal. The following suggestions should be considered in trying to attain both quality and time efficiency when assessing students who are not currently receiving special education services.

1. Set up screening and programming teams at each of the schools in a school system. These teams can help judge which problematic students are likely to be eligible for special education services and therefore, need comprehensive assessment. Members of the same teams can do further screening, thereby reducing the amount of assessment time that school psychologists and educational diagnosticians must give to each student. School psychologists and educational diagnosticians should meet with the screening and programming teams; and principals, special education teachers, school counselors, school nurses, and school social workers should also be available to meet with the regular teachers who are referring students.

This group can also brainstorm strategies to try with students who are unlikely to qualify for special education. These strategies should be tried immediately rather than insisting upon comprehensive assessment of each student discussed by the team.

2. Recognize that the idea of screening and programming teams may encounter initial resistance and that objections to creating these teams must be honestly addressed. A "trial period" for these teams in only one or two schools may have to be the starting point. That way, those who object to the concept will experience (or hear about) quicker services to problematic students (since not all students discussed by the teams will be comprehensively assessed and those who are will be served more quickly). Also, team members have a better chance of experiencing the benefits of a support 
group and the practical advice given by its members.

3. Make sure that the time spent in screening and programming team meetings and related activities (screening, consulting with each other) is spent productively and does not make unreasonable demands on any team member. This effort will require honest negotiations and periodic adjustments (see Fleming \& Fleming, 1983).

4. Establish and communicate clear guidelines for assessment, including sequential steps in the process, functions of the screening and programming teams, and specific responsibilities of various members of the school staff. Use both written and verbal communications, addressed to the board of education, the central office staff, the staff of each school, and parents.

5. Encourage honest discussion of how assessment techniques should be chosen for various types of students who are to receive assessment services. Assessment should not be more comprehensive than is needed for appropriate classification and programming decisions; neither should pressure be exerted to cut corners in collecting information needed for appropriate and beneficial classification and programming decisions.

6. Provide time management training for school psychologists, educational diagnosticians, and members of the screening and programming teams (see Maher, 1982).

7. Request additional assessment personnel if the above steps will not or have not provided for an adequate blend of quantity and quality.

Taking these steps will, in itself, be quite timeconsuming initially. My experience, however, is that by doing so, time problems will be lessened in the future, and more efficient and beneficial assessment will be provided. A final suggestion is to use consultants from universities, the state department of education, and other school systems as needed in planning these steps and implementing them.

In trying to deal with the time problems associated with the requirement to reassess students currently receiving special education services, I offer two suggestions:

1. Eliminate any local requirement that students who no longer need special education services be reassessed before leaving the program (unless reassessment would be useful in planning for their complete return to regular education). Again, do not provide comprehensive assessment services unless they are truly needed for classification and programming purposes.

2. Explore with the state department of education the possibility of adopting a procedure that is referred to in Tennessee as modified reassessments. Under this procedure, a comprehensive reassessment is not required unless one of the following conditions applies (Tennessee Department of Education, 1982, pp.4.17-4.18):

a. The probability of change from the initial evaluation results is high. This is almost always the case with young children.

b. The initial certification of the child as handicapped marginally met the criteria. This does not apply to the (intellectually) gifted.

c. Significant or abrupt changes have occurred in the student's environment, which may affect the status of the handicap.

d. A lack of progress in the student's performance is indicated in his/her annual review of progress in special education.

e. Current information available is insufficient. Adequate information obtained in the annual review (of progress in special education) should include data such as: individual/group achievement scores, observations, mastery of goals/ objectives in the IEP, grades, work samples, and progress reports.

f. The initial assessment was not consistent with the evaluation components and criteria for certification (as handicapped) in the new state Rules, Regulations, and Minimum Standards.

If none of the above conditions apply, a modified reassessment for determining continuing eligibility for special education services may be conducted. These modified reassessments must include (p. 4.18):

1. Personal contact with the student through an observation, interview, and/or testing.

2. Interview with the student's teacher(s).

3. Documentation of the recertification of the student as handicapped and the information on which it is based, written by the appropriate certifying specialist.

State department of education officials in Tennessee hope that allowing modified reassessments will help reduce time requirements for reassessments without sacrificing data needed for appropriate classification 
decisions. In my opinion, these modified reassessments are appropriate with severely handicapped students but less clearly appropriate with mildly handicapped students. And while it may be tempting to cut corners in determining which students are to receive modified reassessments and in actually performing them, I hope these temptations will be resisted. Again, our task is to provide both appropriate and time efficient assessment, not to corrupt the assessment process in the interest of time efficiency alone.

Many rural school systems, as noted earlier, have problems in locating and employing qualified assessment personnel as required by the regulations implementing PL 94-142. Two possible aids in complying with this requirement are:

1. Join or attempt to establish an educational cooperative-an organization in which two or more school systems combine their resources, enabling them to offer services that none of the member systems could offer alone. For example, two neighboring school systems might jointly hire a school psychologist and agree to share the psychologist's services on a $50 / 50$ basis. (Some states, such as Georgia, fund a statewide network of educational cooperatives; in Georgia these organizations are referred to as Cooperative Educational Service Agencies.)

2. Recruit an interested, capable member of the school system's staff to undergo further training toward state certification as a school psychologist, educational diagnostician, or other needed service provider. Ideally, the school system would assume responsibility for tuition costs and cost-of-living allowances (or salary continuation) if the further training would require the person to move from the community for a time or take a leave of absence from regular duties for an internship. The point here, of course, is that assisting a current staff member to become certified in an area of need may be easier and more productive then trying to recruit an "outsider" who may not want to make a long-range commitment to a rural area.

Most school systems probably have difficulty testing students in their native languages as required by the regulations implementing PL 94-142. This difficulty may be based in part on a lack of qualified personnel who speak languages other than English. Furthermore, testing in languages other than English is not appropriate with some tests. Specifically, it is not recommended with tests that have been normed by administering them in English only. Hence, I offer three suggestions:

1. Administer norm-referenced tests in languages other than English only when those tests provide test norms based on non-English administration. For example, administer a norm-referenced test in Spanish only if that test has norms based on administration of that test in Spanish.

2. When it is necessary to assess the intellectual functioning of a non-English speaking student and tests normed in that student's native language are unavailable, use nonverbal measures of intelligence (Gerken, 1978).

3. Consider the possibility that a non-English speaking student might be more appropriately served in a bilingual education program or through arrangements other than the school system's special education program.

A final difficulty in assessment for classification involves the lack of clarity in what is actually required by federal (and state) regulations in implementing nondiscriminatory assessment practices (as partially illustrated by the conflicting court decisions in the Larry $P$. and $P A S E$ cases). I offer five suggestions for dealing with this problem:

1. Ensure that all students who are assessed receive prior hearing and vision screening and that any possible problems identified during screening are further evaluated before proceeding with comprehensive assessment. Correct interpretation of assessment data on students is simply not possible unless data on their auditory and visual acuities are available. If health problems other than hearing and vision difficulties are suspected, these should also be investigated before proceeding with comprehensive assessment. City and county health departments are often quite helpful to school systems in providing hearing and vision assessments and assessments of other possible health problems.

2. Using the best possible professional judgment, select assessment techniques appropriate to the decision to be made about a student and to the student's unique characteristics. For example, norm-referenced tests of intelligence, academic achievement, and adaptive behavior provide the kinds of data that are useful in making classification decisions, and criterion-referenced tests of academic achievement and adaptive behavior often 
provide information helpful to programming decisions. If a norm-referenced test does not provide useful programming information, do not use it as an aid to programming decisions. Similarly, criterion-referenced tests are unlikely to provide information useful for classification decisions and should not be used for that purpose. In choosing tests appropriate to student characteristics, tests that require lengthy verbal responses should not be used with speech-impaired students and tests requiring fine motor skills should not be used with students with motor impairments. Finally, whenever possible try to use tests with adequate reliability, validity, and norms. Since choices of this type require detailed analyses of test appropriateness, readers are urged to consult references such as Helton et al. (1982), Sattler (1982), and Salvia and Ysseldyke (1981) for evaluative comments on a number of specific tests.

3. Take a conservative approach to judgments about students' eligibilities for special education services. Do not classify students as handicapped unless they clearly meet state eligibility criteria. Although a conservative approach to classification decisions will help a school system avoid charges of discriminatory assessment and classification practices, I am not advocating that ineligible students be left to "sink or swim" in their regular classrooms. Instead, investigate other possible sources of assistance to them such as Chapter 1 (formerly Title I) programs or bilingual education programs. In addition, the school screening and programming teams can provide direct and consultative services appropriate to these students' needs.

4. Work hard to make special education services as effective as possible for eligible students. Placement of students in special education programs will less likely be seen as discriminatory if the programs are genuinely helpful.

5. Keep up with changes in state and federal laws and regulations and with court decisions. These changes and decisions determine the legal context for assessment and special education services at any point in time.

\section{Assessment for Programming}

Any related service(s) a student needs in order to benefit from special education must be specified in his or her IEP and provided without cost to parents. The regulations implementing PL 94-142 list the following related services to be considered for inclusion in an IEP: audiology, counseling services, early identification of handicapped children, medical services required to classify a student as handicapped, occupational therapy, parent counseling and training, physical therapy, psychological services, recreational services, school health services, speech pathology services, and transportation. Each of these is defined in the regulations (Education of Handicapped Children, 1977, pp. 42479-42480), and the regulations further indicate that other, nonlisted services may have to be provided.

School officials understandably have expressed concern about including related services in IEPs, largely because school systems have to provide them using school personnel or pay outside agencies or practitioners for these services. Of course, related services do not have to be included in IEPs unless they are seen as necessary for students to benefit from special education. The question of whether any of the related services is needed for a specific student often involves a difficult prediction, which in turn requires honest professional judgments. Three suggestions may be helpful:

1. If services are seen as essential to progress in special education, include them in IEPs. If services are judged to be helpful but not essential, do not include them. Instead, inform parents that the services are seen as desirable rather than essential, and assist parents in locating such services.

2. Whenever appropriate, use school personnel; including members of each school's screening and programming team, to provide related services. This is more convenient and entails less cost than using mostly outside agencies and practitioners.

3. Consider seeking interagency agreements and state legislation that would help spread the costs of related services to other state agencies (such as community mental health centers and state hospitals for emotionally disturbed and mentally retarded children).

The regulations implementing PL 94-142 require that handicapped students be educated in least restrictive environments.Four suggestions may be of help in dealing with the least restrictive environment requirement:

1. Carefully consider the degrees to which handicapped students will be able to participate in classes and activities with nonhandicapped peers. Make judgments about least restrictive environments on a student-by-student basis rather than in terms of students' handicapping conditions or administrative considerations. 
2. Help all members of the school community (board of education, central office staff, principals, teachers, parents) to understand the least restrictive environment requirement.

3. Make consultative services readily available to principals and teachers to help them cope more successfully with perceived problems resulting from placement of students in least restrictive environments. Members of each school's screening and programming teams might be especially helpful in providing such services.

4. Provide social skills training to handicapped students who require it in order to experience social acceptance from nonhandicapped peers (Gresham, 1982). Such training should occur both prior to students' placements with nonhandicapped peers and following the placements (Strain \& Shores, 1983). Again, members of the school's screening and programming team can help, by directly providing social skills training.

Finally, the regulations implementing PL 94-142 require that each student's IEP be reviewed at least annually and modified as needed. Although this is a procedural requirement that is not especially difficult to honor, reviews must be done carefully rather than perfunctorily. Two suggestions illustrate my concerns:

1. Develop and modify IEPs in terms of knowledge of students' characteristics and effective teaching strategies. General teaching strategies that are backed by little research evidence for their effectiveness should not be used in the first place (Kaufman \& Kaufman, 1983). In addition, strategies that are not helping a student progress should be modified as soon as possible (Helton et al., 1982). This requires frequent monitoring of student progress.

2. Involve members of the school's screening and programming team in the initial development of IEPs and in their annual (or more frequent) review. This step helps ensure that full knowledge of students' characteristics and progress is brought to decision making and that continuity in services to students is maintained.

\section{Procedural Requirements}

A number of procedural requirements contained in the regulations implementing PL 94-142 (Education of Handicapped Children, 1977, pp. 42490-42496) are intended to promote fairness to parents and students in the delivery of assessment and special education services. Among the most significant of these requirements are those that provide for written parental consent to initial assessment and to initial special education placement of students, prior notice to parents before schools take (or fail to take) important actions affecting students' educational programs, parental access to students' records, and due process hearings.

Probably the most important stance in complying with these requirements is that school personnel accept parents as partners in the decision making process and try to treat them as they would wish to be treated if their roles were reversed. Increased and improved collaboration between schools and parents is likely to lead to increased educational progress on the part of handicapped students. If this occurs, the time spent in frequent, honest collaboration is well worth the investment. In this spirit, I offer the following specific suggestions:

1. Try to ensure that parental consent for initial assessment and initial placement of each handicapped student is obtained only after parents clearly understand what is being proposed and voluntarily agree to it.

2. Attempt to use mediation of parent-school disagreements to avoid, if possible, the time, expense, and strain of due process hearings.

3. Respectfully maintain your positions as professionals if you feel that you can honorably defend them in due process hearings.

4. Consider initiating due process hearings or other appropriate actions if you believe, in certain instances, that parents are blocking needed services to their children and if efforts at mediation have failed.

\section{Ethical Considerations in Assessment}

While we are often preoccupied with our legal responsibilities to handicapped children, we also face a number of ethical issues in our efforts to provide services to them. Frith (1981) has described a number of instances in which the needs of handicapped students are seen as conflicting with the administrative, financial, and logistical needs of school systems. Conflicts of this nature may necessitate extremely difficult decisions.

As an aid to making such decisions, both a "Code of Ethics" and a set of "Standards for Professional Practice" have been adopted and published by the Council for Exceptional Children (1983a, 1983b). These documents are viewed as binding on the professional 
activities of CEC members: "Members of the special education profession are responsible for upholding and advancing these principles" (Council for Exceptional Children, 1983a, p. 205). Also, these documents unequivocally stress the need for special educators to abide by laws and regulations governing services to handicapped students. Similarly, support service professionals such as school psychologists are often members of professional organizations having their own ethical codes (e.g., American Psychological Association and National Association of School Psychologists). Hence, school staff members may approach ethical issues from a variety of viewpoints.

Despite the diversity of ethical perspectives that may be present in a school staff, ethical obligations are presented here only from the position of the Council for Exceptional Children documents mentioned. This should be sufficient, in any case, as the CEC, APA, and NASP codes and standards overlap somewhat and have no apparent contradictions. Readers who are interested in the specific content of ethical codes in psychology should consult "Ethical Principles of Psychologists" (American Psychological Association, 1981) and "Principles for Professional Ethics" (National Association of School Psychologists, 1978).

The CEC Code of Ethics includes directives to: (1) promote educational and other quality of life opportunities for handicapped students; (2) exercise objective professional judgment in the delivery of services; (3) uphold and improve laws, regulations, and policies impacting special education services; and (4) avoid condoning or participating in unethical, illegal, or other acts that violate professional standards (Council for Exceptional Children, 1983a, p. 205).

This ethical code has, in turn, been translated into "Standards for Professional Practice" (Council for Exceptional Children, 1983b, pp. 206-209). The Standards include directives to:

1. Use assessment techniques and procedures that are nondiscriminatory.

2. Monitor inappropriate placements of students in special education programs, and correct procedures that lead to inappropriate placements.

3. Intervene when a colleague's behavior is seen as detrimental to handicapped students.

4. Provide accurate information and data to administrators, colleagues, and parents to aid in decision making.

5. Inform parents of their students' educational rights and proposed or actual practices that violate those rights.

6. Use methods and curricula that are effective in meeting the needs of handicapped students.

7. Report to administrators when resources are inadequate for the delivery of services, and promote corrective action.

8. Recognize the competencies of members of other disciplines.

Taken together, these directives support many of the provisions contained in the regulations implementing $\mathrm{PL}$ 94-142 and also reinforce some of the suggestions previously offered in this article. Some additional specific suggestions for ethical practice are listed below. These, I believe, are compatible with the APA and NASP ethical codes mentioned above, as well as the CEC "Code of Ethics" and "Standards for Professional Practice."

1. Carefully evaluate your own understandings and skills and engage only in activities in which you are competent. Refer students to other professionals when students require services that other professionals are more competent to provide.

2. Avoid altering or manipulating assessment results in order to qualify students for special education services. Instead, try to promote sufficient flexibility in how data are used in decision making to promote student welfare.

3. Encourage those who have provided assessment services to specific students to participate in meetings where decisions about those students are to be made. Participation prevents misunderstandings of assessment results, allows assessment personnel to ensure that their results are not misused, and enables their expertise in classification and programming to be used in promoting student welfare.

4. Enlist the participation of assessment personnel and others in attempts to resolve conflicts between ethical obligations and financial and administrative considerations. Try to find approaches that better balance legal, ethical, and administrative considerations than approaches previously used.

\section{Available Assessment Techniques}

In responding to the PL 94-142 regulations requiring that students be assessed in all areas related to their suspected disabilities, Helton et al. (1982) have described specific assessment techniques in the following assessment domains: health factors (including auditory and visual acuity); general intellectual functioning; modality 
(or psychoeducational processing) skills; academic functioning; social/emotional functioning; adaptive behavior; and environmental influences on school coping. Salvia and Ysseldyke (1981) also have devoted chapters to assessment techniques appropriate to most of these domains, and in addition have included chapters on the assessment of school readiness and on diagnostic systems.

The point here is that numerous assessment techniques-far too many to discuss in this article-are available for each of these assessment domains. Thus, I provide brief discussions of most of these assessment domains and mention only some representative assessment techniques associated with them. In efforts to choose appropriate assessment techniques, readers are again urged to consult sources such as Helton et al. (1982), Salvia and Ysseldyke (1981), and Sattler (1982).

\section{Health Factors}

As previously indicated, I believe that assessment of all referred students' auditory and visual acuities is essential to appropriate assessment practice. Auditory acuity is typically assessed using audiometric techniques. Visual acuity is typically assessed using a Snellen Chart and/or an apparatus such as the Keystone Telebinocular Instrument. The Keystone provides a more comprehensive assessment of visual acuity and is recommended, whenever possible, over less comprehensive procedures such as the Snellen Chart, which measures only farpoint vision. If screening for other health factors, the System of Multicultural Pluralistic Assessment (Mercer, 1979) provides several instruments for this purpose. Helton et al. (1982) and Salvia and Ysseldyke (1981) offer descriptions of these instruments.

\section{General Intellectual Functioning}

Assessment of general intellectual functioning is required when a student is suspected to be learning disabled or mentally retarded according to the regulations implementing PL 94-142. It also may be required to establish whether a student with a sensory, motor, or other health impairment may additionally be mentally retarded and, hence, multihandicapped. Further, it may be required in determining whether a student is primarily seriously emotionally disturbed or primarily mentally retarded, or possibly both.

Assessment of general intellectual functioning for purposes of classification usually involves administration of one of the following: the Stanford-Binet Intelligence Scale, Form L-M (Terman \& Merrill, 1973), the Wechsler
Preschool and Primary Scale of Intelligence (Wechsler, 1967), the Wechsler Intelligence Scale for ChildrenRevised (Wechsler, 1974), or the Wechsler Adult Intelligence Scale-Revised (Wechsler, 1981). Other instruments for assessing intellectual functioning may be particularly appropriate for deaf, blind, and motorhandicapped students (see Gerken, 1979). In addition, a new test of cognitive functioning, the Kaufman Assessment Battery for Children (Kaufman \& Kaufman, 1983a, 1983b) is currently attracting great attention.

The Kaufman Assessment Battery for Children is described as appropriate for students $2 \frac{1}{2}$ to $12 \frac{1}{2}$ years of age and is based on research in cognitive psychology and neuropsychology. Two of its three scales (Simultaneous Processing and Sequential Processing) are designed to assess students' information processing styles, and knowledge of students' performances on these scales is thought to be useful for both classification and programming purposes. A mental processing composite score reflects performance on both of these scales. A third scale, Achievement, is designed to assess the degree to which students have been able to apply their processing skills to the acquisition of various types of learning tasks, including arithmetic and reading tasks (Kaufman \& Kaufman, 1983a, 1983b). If the K-ABC proves as useful in classification and programming as its authors suggest, it will represent a valuable addition to the Stanford-Binet Intelligence Scale and the Wechsler scales for preschoolers and children.

\section{Modality Skills}

Assessment of modality skills for classification and programming purposes is a complex and controversial topic. Modality skills refer to a student's abilities to interpret sensory information, relate that information to previously acquired information, and respond to that information. The definition of a specific learning disability contained in the regulations implementing PL 94-142 implies that such skills should be assessed in classifying students as learning disabled (Education of Handicapped Children, 1977, pp. 42478-42479). Such a requirement, however, is not specifically contained in the federal regulations, and some states (such as Tennessee) do not require the assessment of modality skills in classifying students as learning disabled.

In addition, debate continues on whether the assessment of modality skills promotes effective programming practices. I am not persuaded that it does, since little research evidence indicates that either attempts to strengthen students' weaknesses in modality skills or 
attempts to "work around them" in teaching lead to improvements in academic achievement (see Kaufman \& Kaufman, 1983c). Techniques typically used to assess modality skills include the Bender Visual-Motor Gestalt Test (Bender, 1938), the Frostig Developmental Test of Visual Perception (Frostig, LeFever, \& Whittlesey, 1966), the Goldman-Fristoe-Woodcock Auditory Skills Test Battery (Woodcock, 1976), the Visual-Aural Digit Span Test (Koppitz, 1977) and the Illinois Test of Psycholinguistic Abilities (Kirk, McCarthy, \& Kirk, 1968).

\section{Academic Functioning}

The regulations implementing PL 94-142 require that assessment of academic functioning be done for classification purposes with students suspected of being learning disabled. In addition, assessment of academic functioning is required with all types of handicapped students for programming purposes. Therefore, this is an extremely important assessment domain. In general, norm-referenced tests of academic functioning are useful for classification, and criterion-referenced tests in this domain are useful for programming.

Examples of the former tests are the Wide Range Achievement Test (Jastak \& Jastak, 1978) and the Peabody Individual Achievement Test (Dunn \& Markwardt, 1970): Examples of the latter include the Criterion Tests of Basic Skills (Lundell, Evans, \& Brown, 1976) and the Brigance Diagnostic Inventory of Basic Skills (Brigance, 1977). Salvia and Ysseldyke (1981) have provided extensive descriptions of diagnostic tests in reading and mathematics, and also of tests of oral and written language (including spelling and writing).

\section{Social/ Emotional Functioning}

Assessment of social/emotional functioning is required by the regulations implementing PL 94-142 for classification of students as seriously emotionally disturbed. Assessing students in this domain may also be necessary to determine if their school problems are primarily the result of a learning disability or emotional disturbance or if they are both emotionally disturbed and experiencing another handicapping condition (multihandicapped). Assessment in this domain may also aid programming decisions for students with a variety of handicaps.

A number of general approaches can be taken for assessing social/emotional functioning. Which of these approaches is most appropriate is the subject of rather heated controversy. Specifically, social/emotional functioning may be assessed through the use of behavior checklists completed by adults who have had extensive contact with a student, self-report instruments (in which a student answers questions about himself/herself), direct behavioral observations of a student, and projective techniques (in which a student responds to ambiguous test materials such as inkblots).

Examples of behavior checklists include the Burks' Behavior Rating Scales (Burks, 1977) and the Walker Problem Behavior Identification Checklist (Walker, 1970). Both of these instruments are norm-referenced and, hence, provide data on the relative severity of a student's behavior problems for classification purposes. Helton et al. (1982) have suggested that data from such instruments be supplemented with direct behavioral observation of a student as a means of both crosschecking data used for classification and collecting additional information for programming. Direct behavioral observation may be conducted using observation systems such as the Ecological Assessment of Child Problem Behavior (Wahler, House, \& Stambaugh, 1976). The use of both behavior checklists and direct behavioral observation is recommended by Helton et al. (1982) as an appropriate approach to the assessment of social/ emotional functioning and is compatible with their behavioral approach to programming.

Examples of self-report instruments include the PiersHarris Children's Self-Concept Scale (Piers \& Harris, 1969) and the California Psychological Inventory (Gough, 1969). The former attempts to measure a student's self-concept from that student's answers to a number of specific questions, and the latter is seen as a test of general personality and emotional development (Salvia \& Ysseldyke, 1981). Although the use of selfreport instruments may enrich our understanding of students' personalities, I favor the use of behavior checklists and direct behavioral observation for classification and particularly for programming purposes (see Helton et al., 1982).

The use of projective techniques in social/emotional assessment is quite controversial. Psychodynamically oriented psychologists often consider these techniques essential (see Obrzut \& Zucker, 1983), and behaviorally oriented psychologists often view them as having questionable value (see Helton et al., 1982). Projective techniques such as the Rorschach Technique (Rorschach, 1942) and the Thematic Apperception Test (Murray, 1943) should be used only by psychologists well versed in the psychodynamic approach to personality and only after extensive training in their use. 


\section{Adaptive Behavior}

Assessment of adaptive behavior is required by the regulations implementing PL 94-142 for classification of students as mentally retarded, in which students must demonstrate significantly deficient functioning in both intelligence and adaptive behavior. For classification purposes, norm-referenced measures of adaptive behavior such as the Vineland Social Maturity Scale (Doll, 1965), the Adaptive Behavior Inventory for Children (Mercer \& Lewis, 1977), and the AAMD Adaptive Behavior Scale-Public School Version(Lambert, Windmiller, Cole, \& Figueroa, 1975) may be appropriate. Each of these measures has strengths and weaknesses (see Helton et al., 1982). Because of this, a new version of the VSMS, the Vineland Adaptive Behavior Scales, has generated much interest. This new instrument is designed for both classification and programming purposes, and it attempts to measure adaptive behavior in both home and school settings (American Guidance Service, 1984). Critierion-referenced measures of adaptive behavior such as the Cain-Levine Social Competency Scale (Cain, Levine, \& Elzey, 1977) provide information useful for programming with mentally retarded students. For a detailed discussion of the assessment of adaptive behavior, see Coulter and Morrow (1978).

\section{Environmental Influences on School Coping}

Assessment of environmental influences on school coping is required by the regulations implementing PL 94-142 for the classification of students as learning disabled. Specifically, students are not to be classified as learning disabled if their learning problems are primarily the result of environmental, cultural, or economic disadvantage (Education of Handicapped Children, 1977, pp. 42478-42479). Determining whether such factors are present and, if so, whether they are the primary cause of a student's learning problems obviously requires knowledge of that student's life circumstances and judgments about the impact of those circumstances. In making such judgments, I again recommend that Chapter 1 or other nonspecial education services be considered when life circumstances (rather than a learning disability) may be the primary causes of a student's learning problem.

Helton et al. (1982) also proposed that environmental influences be assessed with all referred students for programming purposes. They suggested that a number of environmental influences such as general school climate, nature of the school curriculum, teacher behaviors, peer influences, and home influences be considered when making programming decisions. Their point is that environmental influences that are interfering with school progress should be reduced, if possible, and that positive influences on school performance should be increased, if possible. Readers who are interested in specific techniques for assessing environmental influences should consult sources such as Helton et al. (1982) and Smith, Neisworth, and Greer (1978).

\section{Diagnostic Systems}

Diagnostic systems represent the efforts of test authors and publishers to combine measures appropriate to more than one assessment domain into a single package. For example, the Kaufman Assessment Battery for Children (Kaufman \& Kaufman, 1983a, 1983b), mentioned earlier, contains measures of both cognitive functioning and achievement.

Similarly, the aforementioned System of Multicultural Pluralistic Assessment (Mercer, 1979) contains measures of health factors (including auditory and visual acuity), intellectual functioning (the Wechsler Intelligence Scale for Children-Revised or WISC-R), and adaptive behavior (the Adaptive Behavior Inventory for Children). Hence, this system provides more comprehensive assessment of students than do single test instruments.

The SOMPA also was designed to promote nondiscriminatory classification of economically disadvantaged and culturally different students. Specifically, this system is intended to help prevent the misclassification of students as mentally retarded, by providing an estimate of a student's intellectual potential. The estimate is referred to as an "estimated learning potential" (ELP) score. The ELP score is based on how well the student performs on the WISC-R compared to the predicted WISC-R performances of other children in the same ethnic group who are judged to have experienced similar sociocultural backgrounds. In essence, the ELP score compares the student to children thought to have had similar life circumstances. This is in contrast to the usual WISC-R IQ scores, which compare a student's performance on the WISC-R to the WISC-R performances of children in general. Mercer (1979) has recommended that ELP scores be used instead of the usual WISC$\mathrm{R}$ IQ scores in determining whether economically disadvantaged and culturally different students should be classified as mentally retarded. Much controversy surrounds the use of ELP scores. Interested readers might want to consult Helton et al. (1982) and Salvia and Ysseldyke (1981) for further discussion.

The Woodcock-Johnson Psychoeducational Battery 
(Woodcock, 1978) is a third example of a diagnostic system. It is designed to assess cognitive ability, scholastic aptitude, academic achievement, and interests in persons 3 to 80 years of age (Salvia \& Ysseldyke, 1981, p. 335). It, like the System of Multicultural Pluralistic Assessment (Mercer, 1979) is complex. Interested readers are referred to Salvia and Ysseldyke (1981) for further information. Those authors made the point that no diagnostic system is likely to provide all the information needed on a referred student (p. 343).

\section{SEQUENCING ASSESSMENT AND CHOOSING ASSESSMENT TECHNIQUES}

Helton et al. (1982) and Helton and Workman (1982) have advocated the use of an assessment model or system that integrates the needs for assessment to provide adequate information for classification and programming and, at the same time, to be as time efficient as possible. This system, shown schematically in Figure 1, is referred to as a branching assessment system.

\section{The Branching Assessment System}

The branching assessment system is designed primarily for mildly handicapped students and only for the assessment of students judged by the school's screening and programming team as likely to be eligible for special education services. Students who are unlikely to be eligible for special education services should receive assistance in their regular classrooms. Those who do not benefit from such assistance can, of course, be reconsidered for comprehensive assessment at later dates.

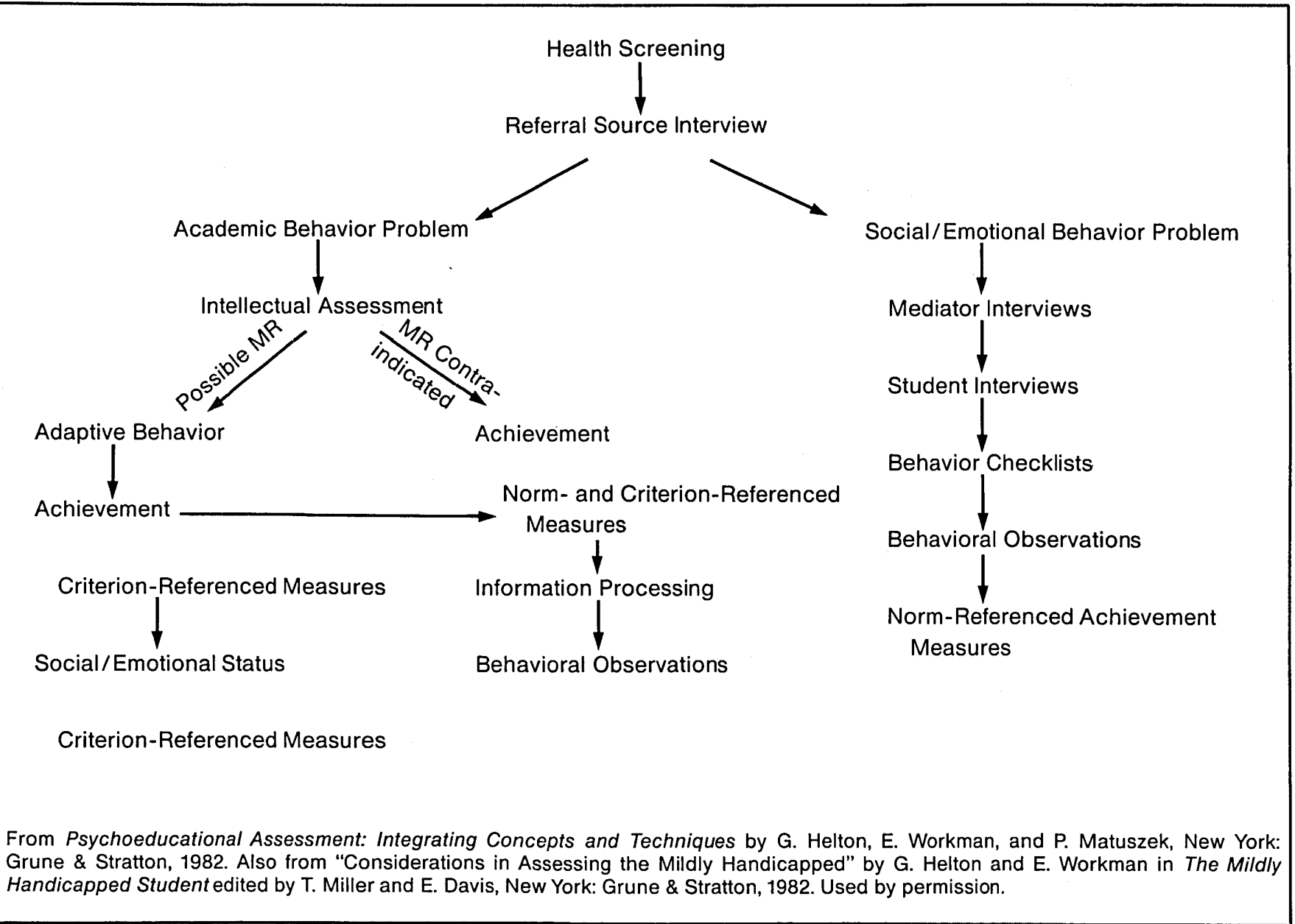


This procedure is designed to save time by not providing comprehensive assessment to all problematic students while, at the same time, allowing students who show compelling need for comprehensive assessment to receive it. The system also promotes time efficiency in that it encourages the use of only those assessment techniques actually needed to provide appropriate information for classification and programming decisions.

In this system, all students to receive comprehensive assessment are first screened for hearing and vision difficulties and for any other suspected health problems. Audiometric testing and testing with the Keystone Telebinocular Instrument are recommended, and screening for other health factors could be done with instruments taken from the System of Multicultural Pluralistic Assessment (Mercer, 1979). Again, any possible problems detected during health screening should receive further evaluation before proceeding with comprehensive assessment.

The next step in the system involves a referral source interview, which is completed by the school's screening and programming team. It should include discussion of the student's cumulative folder and samples of his or her schoolwork. If the team determines that a student needs comprehensive assessment, the team judges whether the student's difficulties suggest an academic behavior problem, a social/emotional behavior problem, or both. Accurate judgments are important for two reasons. First, assessment specialists must choose assessment techniques that are actually relevant to the student's problems. Second, assessment time will be increased if incorrect judgments about the nature of the student's problems lead assessment specialists into the wrong branch of the system. Of course, some students do have both academic and social/emotional problems, and assessment techniques from both branches of the system should be used with these students. Also, in some cases assessment specialists will have to switch from one branch of the system to another if, during assessment, they discover that they are in a wrong branch.

If a student is seen as having primarily an academic behavior problem, the next step in the system is to assess his or her intellectual functioning. The Wechsler scale appropriate for the individual's chronological age (Wechsler, 1967, 1974, or 1981) or the Kaufman Assessment Battery for Children (Kaufman \& Kaufman, $1983 \mathrm{a}, 1983 \mathrm{~b}$ ) if the student is $2 \frac{1}{2}$ to $12 \frac{1}{2}$ years of age is recommended for this purpose.

If the student's performance on the measure of intellectual functioning is in the mentally retarded range, the assessment specialist next uses a measure of adaptive behavior to determine if that student can be classified as mentally retarded. (Remember that a student must be deficient in both intellectual functioning and adaptive behavior to be so classified.) I recommend either the Vineland Social Maturity Scale (Doll, 1965) or the Adaptive Behavior Inventory for Children (Mercer \& Lewis, 1977) as a measure of adaptive behavior. The Vineland Social Maturity Scale offers the advantage of norms for students of all ages, while the Adaptive Behavior Inventory for Children is normed only for students ages 5 through 11. The Vineland Adaptive Behavior Scales (American Guidance Service, 1984) may become the instruments of choice in this assessment domain.

If the student's adaptive behavior is also significantly below average and if he or she has no sensory, motor, or other impairments, he or she might be classified as mentally retarded. This student is then assessed for programming purposes. Assessment would include the use of criterion-referenced measures of academic achievement, such as the Brigance Diagnostic Inventory of Basic Skills (Brigance, 1977), and criterion-referenced measures of social/emotional status, such as the behavioral observation system contained in the Ecological Assessment of Child Problem Behavior (Wahler, House, \& Stambaugh, 1976).

If, on the other hand, the student's measured intellectual functioning is above the mentally retarded range, he or she is next assessed with a norm-referenced measure(s) of academic achievement. This assessment is needed to determine whether the student should be classified as learning disabled. For this classification evidence of a significant discrepancy between expected achievement (based on his or her intellectual functioning) and actual achievement must be shown, as measured through norm-referenced achievement testing (Procedures for Evaluating Specific Learning Disabilities, 1977, p. 65083). Either the Wide Range Achievement Test (Jastak \& Jastak, 1978) or the Peabody Individual Achievement Test (Dunn \& Markwardt, 1970) could be used for this purpose. Criterion-referenced measures of achievement, such as the Brigance Diagnostic Inventory of Basic Skills (Brigance, 1977), should also be administered to assist with programming decisions.

Figure 1 also indicates that information processing (or modality) skills can be assessed with students suspected of being learning disabled. If this type of assessment is required in a particular state, it should be done using instruments such as those described earlier as appropriate to this assessment domain. Finally, 
behavioral observations of the learning disabled student are required for classification (Procedures for Evaluating Specific Learning Disabilities, 1977, pp. 65082-65085). These observations can be accomplished through use of the Ecological Assessment of Child Problem Behavior (Wahler, House, \& Stambaugh, 1976) and will be useful for programming as well.

If the screening and programming team sees a student's problems as primarily social/emotional in nature, another branch of the system is entered. Following interviews with mediators (other teachers, parents) and the student, behavior checklists and behavioral observations are used to determine if the student can be classified as seriously emotionally disturbed. I recommend use of the Walker Problem Behavior Identification Checklist (Walker, 1970) and the Ecological Assessment of Child Problem Behavior (Wahler, House, \& Stambaugh, 1976). These measures should be useful in making both classification and programming decisions about the student. Finally, norm-referenced achievement measures such as the Wide Range Achievement Test (Jastak \& Jastak, 1978) can be used to estimate achievement levels for programming purposes.

\section{Cautions}

The branching assessment system is only one way of sequencing assessment. Readers should judge it or any other system in terms of their own needs. Specific assessment techniques should be chosen carefully.

I have recommended several specific techniques that I and my colleagues have found helpful. Each, however, has its own strengths and weaknesses, and assessment personnel must judge available techniques for themselves.

\section{SUMMARY AND CONCLUSION}

This article has presented an assessment system and specific assessment techniques appropriate to classification and programming for mentally retarded, learning disabled, and emotionally disturbed students. Readers concerned with the assessment of students with lowerincidence handicapping conditions should consult sources such as Gerken (1979).

Assessment is a complex activity and one that must be adapted to local needs. Though I believe that appropriate and beneficial assessment is possible, I also believe that it requires our best efforts. These efforts must involve blending our individual talents with those of others in each school and also on a system-wide and community-wide basis. If this occurs, our students will surely benefit.

\section{REFERENCES}

Algozzine, B., \& Ysseldyke, J. Special education service for normal children: Better safe than sorry? Exceptional Children, 1981, 48, 238-243.

American Guidance Service. 1984 tests and testing services catalog. Circle Pines, MN: American Guidance Service, 1984.

American Psychological Association. Ethical principles of psychologists. American Psychologist, 1981 36, 633-638.

Bender, L. A Visual-Motor Gestalt Test and its clinical uses (Research Monograph No. 3). New York: American Orthopsychiatric Association, 1938.

Brigance, A. Brigance Diagnostic Inventory of Basic Skills. Woburn, MA: Curriculum Associates, 1977.

Burks, H. Burks' Behavior Rating Scales. Los Angeles: Western Psychological Services, 1977.

Cain, L., Levine, S., \& Elzey, F. Manual for the Cain-Levine Social Competency Scale. Palo Alto, CA: Consulting Psychologists Press, 1977.

Coulter, W. Adaptive behavior and professional disfavor: Controversies and trends for school psychologists. School Psychology Review, 1980, 9, 67-74.

Coulter, W., \& Morrow, H. (Eds.). Adaptive behavior: Concepts and measurements. New York: Grune \& Stratton, 1978.

Council for Exceptional Children. CEC code of ethics. Exceptional Children, 1983, 50, 205. (a)

Council for Exceptional Children. CEC standards for professional practice. Exceptional Children, 1983, 50, 206-209. (b)

Doll, E. Vineland Social Maturity Scale. Circle Pines, MN: American Guidance Service, 1965.

Dunn, L., \& Markwardt, F. Peabody Individual Achievement Test manual. Circle Pines, MN: American Guidance Service, 1970.

Education of handicapped children (Regulations implementing Education for All Handicapped Children Act of 1975). Federal Register, August 23, 1977, pp. 42474-42518.

Fleming, D., \& Fleming, E. Consultation with multidisciplinary teams: A program of development and improvement of team functioning. Journal of School Psychology, 1983, 21, 367-376.

Frith, G. "Advocate" vs. "professional employee": A question of priorities for special educators. Exceptional Children, 1981, 47, 486-492.

Frostig, M., LeFever, W., \& Whittlesey, J. Frostig Developmental Test of Visual Perception. Palo Alto, CA: Consulting Psychologists Press, 1966.

Gerken, K. Performance of Mexican-American children on intelligence tests. Exceptional Children, 1978, 44, 438-443.

Gerken, K. Assessment of high-risk preschoolers and children and adolescents with low-incident handicapping conditions. In G. Phye \& D. Reschly (Eds.), School psychology: Perspectives and issues. New York: Academic Press, 1979.

Gough, H. California Psychological Inventory. Palo Alto, CA: - Consulting Psychologists Press, 1969.

Gresham, F. Misguided mainstreaming: The case for social skills training with handicapped children. Exceptional Children, 1982, $48,422-433$.

Helton, G., Morrow, H., \& Yates, J. Grouping for instruction: 1965, 1975, 1985. Reading Teacher, 1977, 31, 28-33.

Helton, G., Workman, E., \& Matuszek, P. Psychoeducational assessment: Integrating concepts and techniques. New York: Grune \& Stratton, 1982.

Helton, G., \& Workman, E. Considerations in assessing the mildly handicapped. In T. Miller \& E. Davis (Eds.), The mildly handicapped student. New York: Grune \& Stratton, 1982. 
Jastak, J., \& Jastak, S. Wide Range Achievement Tést, manual of instructions. Los Angeles: Western Psychological Services, 1978.

Kaufman, A. Intelligence: Old concepts-new perspectives. In G. Hynd (Ed.), The school psychologist: An introduction. Syracuse, NY: Syracuse University Press, 1983.

Kaufman, A., \& Kaufman, N. Kaufman Assessment Battery for Children, Administration and scoring manual. Circle Pines, MN: American Guidance Service, 1983.(a)

Kaufman, A., \& Kaufman, N. Kaufman Assessment Battery for Children, Interpretative manual. Circle Pines, MN: American Guidance Service, 1983.(b)

Kaufman, N., \& Kaufman, A. Remedial intervention in education. In G. Hynd (Ed.), The school psychologist: An introduction. Syracuse, NY: Syracuse University Press, 1983.(c)

Kirk, S., McCarthy, J., \& Kirk, W. Illinois Test of Psycholinguistic Abilities. Urbana, IL: University of Illinois Press, 1968.

Koppitz, E. The Visual Aural Digit Span Test. New York: Grune \& Stratton, 1977.

Lambert, N., Windmiller, M., Cole, L., \& Figueroa, R. Manual for the public school version of the AAMD Adaptive Behavior Scale. Washington, DC: American Association on Mental Deficiency, 1975.

Larry P. et al. v. Wilson Riles et al. U.S. Dist. Ct., Northern District of California, Case No. C-71-2270 RFP, 1972, 1974, 1979.

Lundell, K., Evans, J., \& Brown, W. Criterion Tests of Basic Skills. San Rafael, CA: Academic Therapy Publications, 1976.

Maher, C. Time management training for providers of special services. Exceptional Children, 1982, 48, 523-528.

Mercer, J. Technical manual. System of multicultural pluralistic assessment. New York: Psychological Corp., 1979.

Mercer, J., \& Lewis, J. SOMPA parent interview manual New York: Psychological Corp., 1977.

Murray, H. Thematic Apperception Test. Cambridge, MA: Harvard University Press, 1943.

National Association of School Psychologists. Principles for professional ethics. Washington, DC: National Association of School Psychologists, 1978.

Obrzut, J., \& Zucker, S. Projective personality assessment techniques. In G. Hynd (Ed.), The school psychologist: An introduction. Syracuse, NY: Syracuse University Press, 1983.

Parents in Action on Special Education (PASE) v. Joseph P. Hannon. U.S. Dist. Ct., Northern District of Illinois, Eastern Division, No.
74 (3586), July, 1980.

Piers, E., \& Harris, D. The Piers-Harris Children's Self-Concept Scale. Nashville: Counselor Recordings and Tests, 1969.

Procedures for evaluating specific learning disabilities. Federak Register, December 29, 1977, pp. 65082-65085.

Reschly, D. Legal issues in psychoeducational assessment.In G. Hynd (Ed.), The school psychologist: An introduction. Syracuse, NY: Syracuse University Press, 1983.

Rorschach, H. Psychodiagnostics. Berne, Switzerland: Verlag Hans Huber, 1942.

Salvia, J., \& Ysseldyke, J. Assessment in remedial and special education (2nd ed.). Boston: Houghton Mifflin, 1981.

Sattler, J. Assessment of children's intelligence and special abilities. Boston: Allyn \& Bacon, 1982.

Smith, R., Neisworth, J., \& Greer, J. Evaluating educational environments. Columbus, OH: Charles E. Merrill, 1978.

Strain, P., \& Shores, R. A reply to misguided mainstreaming. Exceptional Children, 1983, 50, 271-273.

Tennessee Department of Education. Student evaluation manual. Nashville, TN: Tennessee.Department of Education, 1982.

Terman, L., \& Merrill, M. Stanford-Binet Intelligence Scale, manual for the third revision, form L-M, 1972 norms edition. Boston: Houghton-Mifflin, 1973.

Wahler, R., House, A., \& Stambaugh, E. Ecological assessment of child problem behavior: A clinical package for home, school, and institutional settings. New York, Pergamon Press, 1976.

Walker, H. Walker Problem Behavior Identification Checklist. Los Angeles: Western Psychological Services, 1970.

Weatherly, R., \& Lipsky, M. Street-level bureaucrats and institutional innovations: Implementing special education reform. Harvard Educational Review, 1977, 47, 171-197.

Wechsler, D. Marual for the Wechsler Preschool and Primary Scale of Intelligence. New York: Psychological Corp., 1967.

Wechsler, D. Manual for the Wechsler Intelligence Scale for ChildrenRevised. New York: Psychological Corp., 1974.

Wechsler, D. Manual for the Wechsler Adult Intelligence ScaleRevised. New York: Psychological Corp., 1981.

Woodcock, R. Goldman-Fristoe-Woodcock Auditory Skills Test Battery, technical manual. Circle Pines, MN: American Guidance Service, 1976.

Woodcock, R. Woodcock-Johnson Psychoeducational Battery. Boston: Teaching Resources, 1978.

\begin{tabular}{|c|c|c|}
\hline \multicolumn{2}{|r|}{ INDEX } & - VOLUME 16 \\
\hline Author Index & 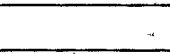 & Chronological Index of Titles \\
\hline $\begin{array}{l}\text { Appell, Louise S. (Jan. 1984) } \\
\text { Bernstein, Rhoda (Feb. 1984) } \\
\text { Cohen, Sandra (Nov. 1983) } \\
\text { de Bettencourt, Laurie (Nov. 1983) } \\
\text { Finn, David M. (Oct. 1983) } \\
\text { Fortmeyer, Dennis (April 1984) } \\
\text { Harrod, Norma (Sept. 1983) } \\
\text { Hazel, J. Steven (Dec. 1983) } \\
\text { Helton, George B. (May 1984) } \\
\text { Horn, Charles J., Jr. (Oct. 1983) } \\
\text { Hurley, Kathleen M. (Jan. 1984) } \\
\text { Johnston, Janis (Feb. 1984) } \\
\text { Larson, Craig (Feb. 1984) } \\
\text { Mendez de Saman, Lupe (April 1984) } \\
\text { Meyen, Edward L. (Dec. 1983) } \\
\text { Moran, Mary Ross (March 1984) } \\
\text { Pederson, Colleen Smalter (Dec. 1983) } \\
\text { Ruggles, Marilyn (Sept. 1983) } \\
\text { Schumaker, Jean Bragg (Dec. 1983) } \\
\text { Simon, Dennis (Feb. 1984) } \\
\text { Smith, Aliona (Feb. 1984) } \\
\text { Vetter-Zemitzsch, Alice (Feb. 1984) } \\
\text { Whelan, Richard J. (April 1984) }\end{array}$ & . & $\begin{array}{l}\text { Computer Assisted Instruction: } \\
\text { An Educational Tool (Sept. 1983) } \\
\text { Sources of Computing (Oct. 1983) } \\
\text { Teaching Children to be Independent Learners: } \\
\text { A Step-by-Step Strategy (Nov. 1983) } \\
\text { Social Skills Curricula for Mildly Handicapped } \\
\text { Adolescents: A Review (Dec. 1983) } \\
\text { Individualizing Instruction with } \\
\text { Microcomputer Software (Jan. 1984) } \\
\text { The On Campus Program: A Systemic/Behavioral } \\
\text { Approach to Behavior Disorders in High School } \\
\text { (Feb. 1984) } \\
\text { Excellence at the Cost of Instructional Equity? } \\
\text { The Potential Impact of Recommended Reforms } \\
\text { Upon Low Achieving Students (March 1984) } \\
\text { Oh! Those Wonderful Feelings } \\
\text { (The Relationship between Pupil Affect } \\
\text { and Achievement) (April 1984) } \\
\text { Guidelines for Assessment in Special } \\
\text { Education (May 1984) }\end{array}$ \\
\hline
\end{tabular}

